\title{
Application of IAC Yokohama System For Reporting Breast Fine Needle Aspiration- A Retrospective Study
}

\author{
Upender Sharma, Atul Beniwal, Sonam Sharma, Ajit Singh and Hemlata T Kamra* \\ Department of Pathology, Kalpana Chawla Govt. Medical College, Karnal (Haryana)
}

\begin{abstract}
Background: Breast cancer is one of the most common cancers worldwide in females and is an important cause of mortality and morbidity. FNAC is a safe, reliable, sensitive, specific, time saving and cost effective procedure useful in the diagnosis of carcinoma breast. It helps the surgeon in planning the treatment, and thereby reducing the delay in treatment. The primary aim of this study is to find out the spectrum of breast lesions on fine needle aspiration cytology based on IAC Yokohama system in a tertiary care hospital of north central Haryana.

Methods: This is a retrospective study carried out in a tertiary care hospital of north-central Haryana and included 417 patients of palpable breast lumps presented in the Department of Pathology for FNAC during January 2018 to December 2019. FNAC was done under all aseptic conditions and various cytomorphological patterns were analysed according to the IAC Yokohama system for reporting breast fine needle aspirations.
\end{abstract}

Result: Of the 417 cases included in the study, 328 cases were benign, 04 were atypical probably benign, 04 were suspicious for malignancy, 64 cases were malignant and 17 cases were inadequate for opinion. Fibroadenoma was found to be the most common breast lesion. Overall benign breast lesions are much more common than malignant lesions.

Conclusion: FNAC is a useful tool to diagnose malignant lesions of the breast and help the surgeon in differentiating benign and malignant lesions. Early diagnosis aid in effective management of malignant lesions of the breast and thereby reducing the mortality in these patients.

Keywords: Fine Needle Aspiration Cytology, Breast, Benign, Fibroadenoma, Carcinoma, Gynaecomastia

\section{Introduction}

Breast cancer is one of the most common cancers worldwide in females and is an important cause of mortality and morbidity. ${ }^{[1-2]}$ Techniques used to diagnose breast lesions include clinical breast examination, breast imaging, and breast cytology. ${ }^{[3-4]}$ Fine-needle aspiration cytology is the most reliable component of this triple test assessment of breast lesions due to its high sensitivity, specificity, accuracy and low cost. ${ }^{[5-6]}$ In recent years, the focus on breast cancer has shifted from treatment to early diagnosis with the detection of proliferative or borderline breast diseases. ${ }^{[7]}$ There are wide varieties of breast pathologies. It is postulated that the non-proliferative and inflammatory breast lesions do not increase the risk of cancer. There is mild to moderate risk with proliferative breast disease not showing atypia and with atypia respectively and higher risk of malignancy with carcinoma in situ ${ }^{[8]}$ The major goal of FNAC is to differentiate benign from malignant lesions. The success rate of FNAC for obtaining a definite diagnosis depends on whether the lesion is palpable and also its size. FNAC has approximately success rates of $75-90 \%$ for palpable and $35-55 \%$ for non-palpable breast lesions respectively. ${ }^{\left[{ }^{[9]}\right.}$ Therefore, this study was planned to find out the frequency of various types of lesions in palpable breast lumps and to get insights into the morphological patterns of breast lesions through FNAC according to the IAC Yokohama system in a tertiary care hospital of north central Haryana. ${ }^{[10]}$

\section{Materials and Methods}

This is a retrospective study carried out in a tertiary care hospital of north-central Haryana and included 417 patients of palpable breast lumps presented in the Department of Pathology for FNAC from January 2018 to December 2019. All the patients were clinically examined and the procedure of FNAC was explained to them including reliability, limitations and complications of the procedure. Informed consent of the patients was taken. FNA procedure, smear preparation and staining were done as per the standard procedure. Special staining like Ziehl Neelsen stain and PAS were performed wherever required. Smears were examined microscopically for evaluating the cytological findings in all the cases and were classified according to IAC Yokohama system for reporting breast FNAC.

\section{Results}

The age range of the patients was from 13 years to 75 years. The female:male ratio was 11.9:1. Left breast was more commonly affected (53\%) than right breast. Upper outer quadrant was the commonest site of location of lump in both breasts. The spectrum of breast lesions 
on cytomorphological interpretation were categorised according to International Academy of Cytology (IAC) Yokohama system for reporting of breast FNAC (Table 1). It was observed that 328 cases were $(78.65 \%)$ benign, 04 cases $(0.95 \%)$ were atypical probably benign, 04 cases $(0.95 \%)$ were suspicious probably malignant, and 64 cases (15.34\%) were malignant. 17 cases (4.07\%) were inadequate for opinion because of scanty cellularity/ material. Among the benign cases, 54 (16.46\%) were inflammatory and 124 cases $(37.80 \%)$ were benign neoplasm. Among the 328 benign breast lesions (Table 2), 122 [37.19\%] were fibroadenoma on cytology (Fig 1). Fibroadenoma patients were correlated with clinical setting and physical findings. They had solitary firm highly movable mass whereas patients of fibroadenosis

Table 1: IAC Yokohama categorization of cases.

\begin{tabular}{|l|l|}
\hline IAC Yokohama Category & No. of cases \\
\hline Benign & $328[78.65 \%]$ \\
\hline Atypical & $04[0.95 \%]$ \\
\hline Suspicious & $04[0.95 \%]$ \\
\hline Malignant & $64[15.34 \%]$ \\
\hline Inadequate & $17[4.07 \%]$ \\
\hline Total & $\mathbf{4 1 7}$ \\
\hline
\end{tabular}

Table 2: Distribution of benign lesions.

\begin{tabular}{|c|c|}
\hline Benign Lesion & No. of cases \\
\hline Fibroadenoma & $122(37.19 \%)$ \\
\hline Benign Breast Disease, NOS & $80(24.39 \%)$ \\
\hline Fibrocystic disease & $24(7.31 \%)$ \\
\hline Gynaecomastia & $26(7.92 \%)$ \\
\hline Galactocele & $13(3.96 \%)$ \\
\hline Duct Papilloma & $1(0.30 \%)$ \\
\hline Lipoma & $1(0.30 \%)$ \\
\hline Proliferative breast disease & $5(1.52 \%)$ \\
\hline Benign Phyllodes & $2(0.60 \%)$ \\
\hline Inflammatory breast lesion & $54(16.46 \%)$ \\
\hline Total & 328 \\
\hline \multicolumn{2}{|c|}{ Table 3: Distribution of inflammatory lesions. } \\
\hline Inflammatory lesion & No. of cases \\
\hline Acute mastitis/abscess & $35(64.81 \%)$ \\
\hline Granulomatous mastitis & $8(14.81 \%)$ \\
\hline Tubercular mastitis & $3(5.55 \%)$ \\
\hline Fat necrosis & $1(1.85 \%)$ \\
\hline Epidermal inclusion cyst & $6(11.11 \%)$ \\
\hline Duct ectasia & $1(1.85 \%)$ \\
\hline Total & 54 \\
\hline
\end{tabular}

had diffuse lump or nodularity associated with pain. The next commonest cytological diagnoses were benign breast disease, NOS 80 cases $(24.39 \%)$ and inflammatory breast disease 54 cases $(16.46 \%)$, respectively.

Out of 54 cases of benign inflammatory lesions [Table-3] 35 (64.81\%) cases were of acute mastitis/abscesss followed by 8 cases of granulomatous mastitis, 6 cases of epidermal inclusion cyst, 3 cases of tubercular mastitis, 1 case of fat necrosis and 1 case of duct ectasia. Ziehl Neelsen stain was applied to all the cases of granulomatous mastitis but only 3 cases were positive for acid fast bacilli and were labelled as tubercular mastitis. Out of the 64 malignant cases, 62 cases had infiltrating ductal carcinoma (Fig 2, 3), 1 case had mucinous carcinoma and the remaining 1 case had Non-Hodgkin's Lymphoma. 


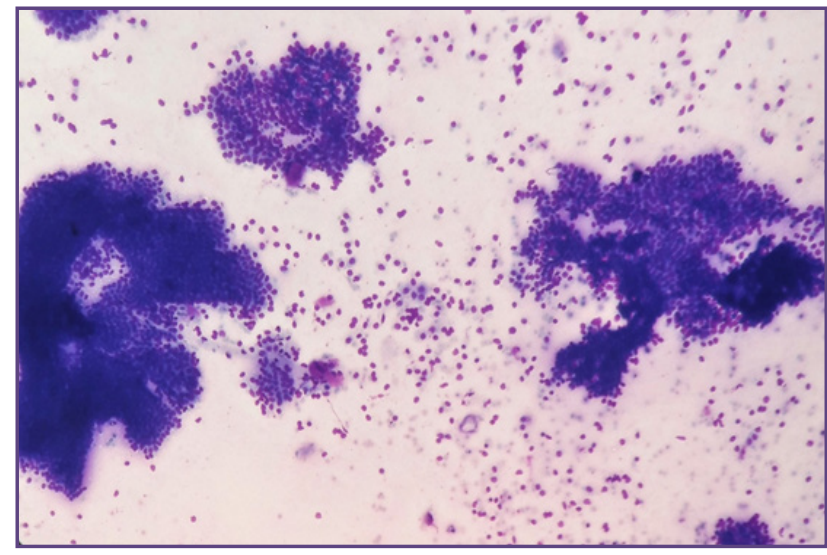

Fig. 1: Cytological smear showing benign cohesive sheets of ductal epithelial cells with numerous bare bipolar nuclei and fibromyxoid stroma in the background (MGG, 100X).

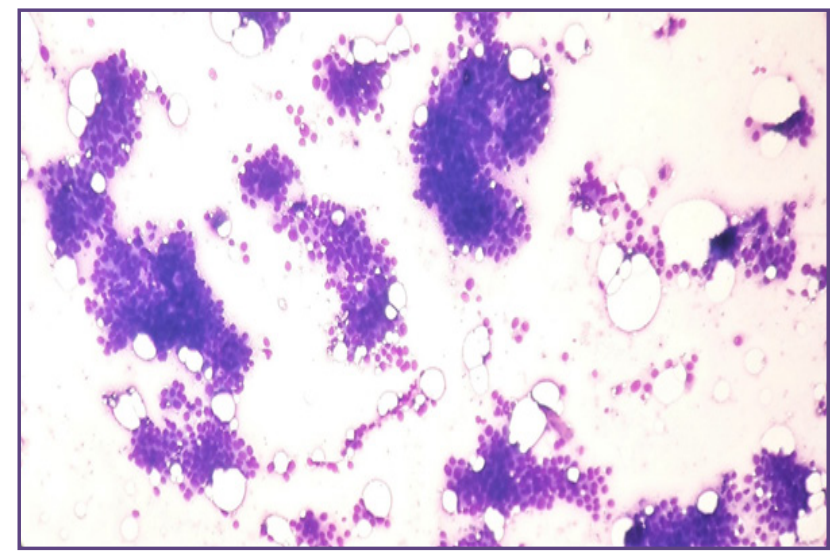

Fig. 2: Cytological smear showing loosely cohesive clusters with singly scattered malignant cells in IDC, NOS (MGG, 100X).

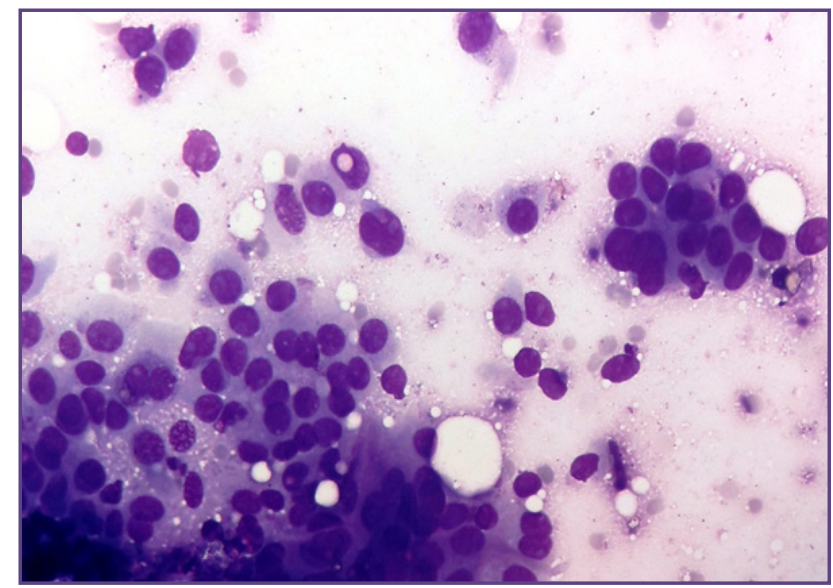

Fig. 3: Cytological smear showing dyscohesive malignant epithelial cells with moderate nuclear pleomorphism in IDC, NOS (MGG, 400X).

\section{Discussion}

The primary objective of the present study was to determine the type and distribution of breast lesions diagnosed by breast cytology according to IAC Yokohama system for reporting of breast FNAC in a tertiary care hospital of north central Haryana. The main goal of FNA is to separate benign and malignant lesions so that early diagnosis helps in management and reduces morbidity and mortality. Breast diseases are more common in women because estrogen cyclically stimulates breast during their reproductive life. In our study benign lesions were much more common (78.65\%) than malignant lesions $(15.34 \%)$ with benign: malignant ratio of 5.12:1 which is in concordance with other studies. ${ }^{[1-14]}$ It has been observed that in Indian rural population the benign breast diseases are 5 to 10 times more common than breast cancers. ${ }^{[1]}$

According to American Cancer society 2002 benign breast conditions causing lumps or tumours are quite common with an estimated 9 out of 10 women showing benign tissue changes if tissue is examined microscopically. ${ }^{[15]} \mathrm{In}$ the present study fibroadenoma was most common of the benign lesions and constituted which is also in concordance with other studies. ${ }^{[16-17]}$ Incidence of fibroadenoma is higher in younger women under 30 . Second most common was benign breast disease, NOS. All cases of galactocele (3.96\%) had history of lactation. Two cases diagnosed of benign phyllodes tumor had predominance of stroma over epithelial component with high stromal cellularity and leaf like stromal fragments. Out of 54 cases of benign inflammatory lesions $35(64.81 \%)$ cases were of acute mastitis/abscesss. These patients had tender lump and some of these also had history of fever. This was followed by 8 cases of granulomatous mastitis, 6 cases of epidermal inclusion cyst, 3 cases of tubercular mastitis, 1 case of fat necrosis and 1 case of duct ectasia. ZN stain was applied to all the cases of granulomatous mastitis but only 3 cases were positive for acid fast bacilli and were labelled as tubercular mastitis.

Epidermal inclusion cyst in breast is very rare. Common sites for epidermal inclusion cyst are head, neck, trunk and extremities. They remain underreported because of their insignificant clinical presentation. ${ }^{[18]}$ Four cases which were diagnosed as atypia of indeterminate significance were possibly benign and had some loose clusters with anisonucleosis. Four cases that were diagnosed as suspicious for malignancy had features of malignancy but cellularity was scanty for definitive comment. Out of the 64 malignant cases, 62 cases had infiltrating ductal carcinoma, 1 case had mucinous carcinoma and the remaining 1 case had Non-Hodgkin's Lymphoma. 
As per GLOBOCON 2015, estimated incidence of breast carcinoma is 155863 which is 10926 more than in 2012 and estimated mortality is 75957 which is 5739 more than that in 2012. In India, for every 2 women newly diagnosed with breast cancer, one lady is dying of it. ${ }^{[19]}$ The incidence of malignancy is variable in various studies depending on the study population is of rural/ urban/ metropolitan cities. ${ }^{[20-21]}$ In our study malignancy is comparatively less as we have catered rural population. Mortality and incidence is relatively lower in developing countries and other parts of globe in comparison to western population. ${ }^{[22]}$ Balkrishna $\mathrm{B}$ Yeole et al in an epidemiological study compared the breast cancer incidence of various countries and found that incidence rates were very high in developed countries. ${ }^{[23]}$ The incidence of breast cancer increases with age, more common in urban population and in women of higher socioeconomic group. They also suggested that apart from genetic causes, change in life style is responsible for increase in incidence of malignant breast lesions.

\section{Conclusion}

Early diagnosis is of paramount importance to decrease the mortality and morbidity associated with breast lesions. FNAC is a highly reliable tool in the assessment of breast lump for the differential diagnoses of benign from malignant tumor and is an excellent diagnostic modality in the context of a multidisciplinary approach. The ability of FNA to differentiate benign and malignant lesions coupled with high sensitivity and specificity gives great psychological relief to the patient as majority of the breast lump lesions are of benign nature.

\section{Acknowledgements}

\section{No}

\section{Funding}

None

\section{Competing Interests}

None

\section{Reference}

1. Siegel RL, Miller KD and Jemal A. Cancer statistics. CA: A Cancer Journal for Clinicians 2015; 65: 5-29

2. Ahmad N, Kalsoom S, Mahmood Z et al. Comparative evaluation of selected sex hormones in premenopausal and postmenopausal women with breast cancer. International Journal of Biosciences(IJB) 2019; 15: 10-13

3. Salzman B, Fleegle S, Tully AS. Common breast problems. Am Fam Physician 2012; 86: 343-49

4. Morris A, Pommier RF, Schmidt WA, Shih RL, Alexander PW, Vetto JT. Accurate evaluation of palpable breast masses by the triple test score. Arch Surg. 1998; 133: 930-4
5. Ngotho J, Githaiga J, Kaisha W. Palpable discrete breast masses in young women: two of the components of the modified triple test may be adequate. S Afr J Surg. 2013;51:58-60

6. Muchiri LW, Penner DW, Adwok J, Rana FS. Role of fineneedle aspiration biopsy in the diagnosis of breast lumps at the Kenyatta National Hospital. East Afr Med J. 1993; 70: $31-33$

7. Strax P. Detection of breast cancer. Cancer 1990; 66: $1336-40$

8. Susan C Lester. The breast. Kumar V, Abbas AK, Aster JC editors. Robbins and Cotran Pathologic basis of disease. Gurgoan: Reed Elsevier India Pvt Ltd; 2015;1043-71

9. Hukkinen K, Kivisaari L, Heikkila PS, et al, Unsuccessful preoperative biopsies, fine needle aspiration cytology or core needle biopsy, lead to increased costs in the diagnostic workup in breast cancer. Acta Oncol 2008; 47:1037-40.

10. Field AS, Raymond WA, Schmitt F. The international academy of cytology Yokohama system for reporting breast fine needle aspiration biopsy cytopathology. 1st ed. Heidelberg: Springer; 2020.

11. M Kumar, K Ray, S Harode, DD Wagh. The Pattern of Benign Breast Diseases in Rural Hospital in India, East and Central African Journal of Surgery 2010; 15:59-64

12. Adesunkanmi, A.R., E.A. Agbakwuru, . Benign breast disease at Wesley Guild Hospital, Ilesha, Nigeria. West Afr. J. Med.2001; 20: 146 -51

13. Chandanwale S, Rajpal M, Jadhav P, Sood S, Gupta K, Gupta $\mathrm{N}$. Pattern of benign breast lesions on fnac in consecutive 100 cases: a study at tertiary care hospital in India IJPBS 2013;4:129-138

14. Panjvani SI, Parikh BJ, Parikh SB, Chaudhari BR, Patel KK, Gupta GS, et al. Utility of fine needle aspiration cytology in the evaluation of breast lesions. J Clin Diagn Res. 2013; 7: 2777-79.

15. Catherine Goehring and Alfredo Morabia.. Epidemiology of Benign Breast Disease, with Special Attention to Histologic Types. Epidemiol Rev 1997; 19: 310-327.

16. Malik R, Bhardwaj VK; Breast lesions in young females. A 20year study for significance of early recognition. Indian J Pathol Microbiol., 2003; 46(4): 559-62.

17. Jyoti Priyadarshini Shrivastava, Alok Shrivastava. "Fine Needle Aspiration Cytology of Breast Lumps with Clinical and Histopathological Correlation: A 2 Year Study in Gwalior, India". Journal of Evolution of Medical and Dental Sciences 2015; 4: 9729-34

18. Chandanwale SS, Gupta K, Dharwadkar AA, Pal S, Buch AC, Mishra N. Pattern of palpable breast lesions on fine needle aspiration: A retrospective analysis of 902 cases. J Midlife Health. 2014; 5(4): 186-191

19. Predictions - Globocan - iarc globocan. iarc. fr/ Pages/ burden_sel.aspx 
20. Pradhan M, Dhakal HP. Study of breast lumps of 2,246 cases by fine needle aspiration. J Nepal Med Assoc 2008; 47: 205-9

21. Mayun AA, Pindiga UH, Babayo UD. Pattern of histopathological diagnosis of breast lesions in Gombe, Nigeria. Niger J Med 2008; 17: 159-62
22. Khan S, Kapoor AK, Khan IU, et al. Prospective study of pattern of breast diseases at epalgunj medical college (NGMC). Nepal Kathmandu Univ Med J 2003; 1: 95-100

23. Balkrishna B Yeole, AP Kurkure. An epidemiological assessment of increasing incidence and trends in breast cancer in Mumbai and other sites in India during the last two decades. Asian Pacific Journal of Cancer Prevention, 2003; 4: 51-56

*Corresponding author:

Dr. Hemlata T Kamra, Professor \& Head, Department of Pathology, Kalpana Chawla Govt. Medical College, Karnal-132001 (Haryana)

Phone: +9108221883255 / 9306514988

Email: hemlatamunde@rediffmail.com

Date of Submission $\quad: 16 / 08 / 2021$

Date of Final Revision : 18/08/2021

Date of Acceptance $\quad:$ 25/08/2021

Financial or other Competing Interests: None.

Date of Publication $\quad: 30 / 08 / 2021$ 